\title{
Further Study of Electric Dust Removal with Transparent Fork Electrodes
}

\author{
Guangming $\mathrm{Wu}^{1 *}$, Dan $\mathrm{Li}^{2}$, Jianxiang Yu${ }^{1}$, Tianlan Yin ${ }^{2}$, Dongdong Feng ${ }^{1}$ \\ ${ }^{1}$ Beijing Institute of Petrochemical Technology, Beijing, China \\ ${ }^{2}$ Beijing University of Chemical Technology, Beijing, China \\ Email: wuguangming@bipt.edu.cn
}

Received 26 December 2014; accepted 28 January 2015; published 30 January 2015

Copyright @ 2015 by authors and Scientific Research Publishing Inc.

This work is licensed under the Creative Commons Attribution International License (CC BY).

http://creativecommons.org/licenses/by/4.0/

(c) (i) Open Access

\begin{abstract}
This study is a continuation of our previous work. In this experiment, transparent tin-doped indium oxide (ITO) fork electrodes with different width and spacing were coated on the glass substrates. The used dust particle size was smaller than 180 mesh. The effects of the electrode width, the electrode spacing, voltage, frequency, waveform, and the duty ratio on the dust removal efficiency were studied. The obtained optimum conditions of dust removal were as follows: voltage was $1500 \mathrm{~V}$, frequency was $15 \mathrm{~Hz}$, square wave, $10 \%$ duty ratio, the electrode width was $0.5 \mathrm{~mm}$, electrodes spacing was $1.3 \mathrm{~mm}$. Our previous experimental results show that the dust removal efficiency would be up to $95 \%$. But in this experiment, under the optimum conditions, the dust removal efficiency could be up to $99 \%$.
\end{abstract}

\section{Keywords}

Transparent Fork Electrode, Dust Removal Efficiency, ITO

\section{Introduction}

With the more and more explorations of the moon, Mars and other planets and the growing popularity of solar energy in the social production, dust removal technology on solar panels has attracted considerable attention and investigation. Among all kinds of known dust removal technologies, growing interest has been focused on electric dust removal technology, because of its high efficiency, clean, no contact and no damage to solar panels, and other advantages. So it has become a hot spot of dust removal research area [1] [2]. Fork electrodes are composed of a series of plus and minus alternate, staggered parallel electrodes, some articles called electric cur-

\footnotetext{
${ }^{*}$ Corresponding author.
} 
tain. Electric curtain are divided into two kinds, one is the standing wave electric curtain, which is ${ }^{1}$ connected to single-phase AC power supply, and the other is the traveling wave electric curtain, which is connected to polyphase AC power supply [3] [4].

Electric dusting was put forward for the first time by Tatom et al. in 1967. Masuda et al. studied the movement of dust particles in fork electrode electric field. Schmidin and Melcher et al. explored a great diversity of application of electric dust removal with fork electrodes [5]-[7]. Mazumder et al. put forward the concept of flexible electrodynamic screen (EDS) based on the traveling wave electric curtain technology, studied the dust removal efficiency in Martian environmental, and proposed the feasibility of EDS applied to photovoltaic system in dusting removal on solar panels [8].

This study is a further exploration of our previous study [9]. Transparent ITO fork electrodes with the same thickness, different width, different spacing were coated on glass substrates and connected to single-phase AC power. The alternating electric field was produced and then the landed dielectric dusts were polarized. The electric force formed by the transient changes of electric field will overcome gravity and dust adhesion strength between the substrate, so the dusts can be removed. The influences of the spacing and width of the fork electrode, voltage, frequency, waveform and duty ratio on dust removal efficiency were investigated in the experiment.

\section{Experiment}

Dust removal experiment device was shown in Figure 1. The light source is a common used fluorescent lamp. The dust removal efficiency can be measured by detecting the light power intensity of substrate under different condition with power detector. Setting the initial light power intensity of ITO fork electrode is A, after placed dust is $B$, after dust removal is $C$, so the dust removal efficiency is defined as: $(C-B) /(A-B) * 100 \%$. The dust used in this experiment is the outdoor natural dust in Beijing Daxing district and the particle size is less than 180 meshes. The selected wavelength of power detector is $514 \mathrm{~nm}$.

\section{Results and Discussion}

\subsection{Orthogonal Table}

Table 1 is orthogonal table of fork electrode dust removal experiment, it can be seen that the dust removal efficiency under the experimental conditions of group $4(10 \mathrm{~Hz}$ frequency, voltage $1500 \mathrm{~V}$, electrode width is 1.5 $\mathrm{mm}$, electrode spacing of $1.6 \mathrm{~mm}$ ) is highest, up to $96.8 \%$. Through range analysis, the effect of voltage on the dust removal efficiency is the largest, the next is the frequency, last is electrode width, and the electrode spacing has minimal impact on dust removal efficiency. This is mainly because the voltage is one of the main influencing factors of electric field intensity, whereas the frequency determines the speed of direction change of electric field intensity.

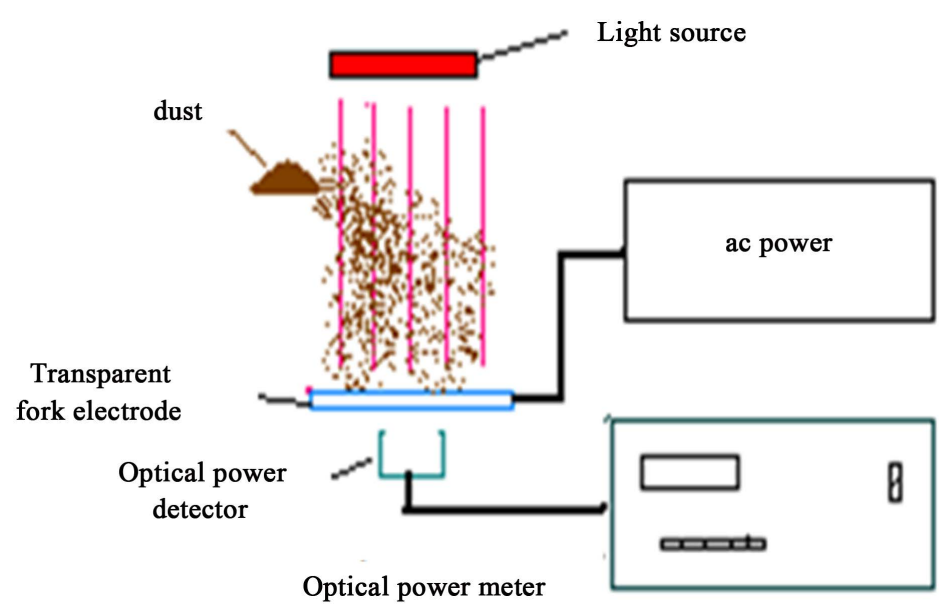

Figure 1. Schematic diagram of dust removal experiment device.

${ }^{1}$ Scientific research project of Beijing municipal education commission, China (KM201410017003). 
Table 1. Orthogonal table of fork electrode dust removal experiment.

\begin{tabular}{|c|c|c|c|c|c|}
\hline \multirow{2}{*}{ Number } & \multicolumn{4}{|c|}{ Factors } & \multirow{2}{*}{$\begin{array}{c}\text { Result } \\
\text { Dusting Efficiency }\end{array}$} \\
\hline & Frequency/Hz & Voltage/V & Electrode Width/mm & Electrode Gap/mm & \\
\hline 1 & 10 & 500 & 0.1 & 0.5 & $81.80 \%$ \\
\hline 2 & 10 & 800 & 0.5 & 0.8 & $61.50 \%$ \\
\hline 3 & 10 & 1100 & 1 & 1.3 & $85.90 \%$ \\
\hline 4 & 10 & 1500 & 1.5 & 1.6 & $96.80 \%$ \\
\hline 5 & 20 & 500 & 0.5 & 1.3 & $55 \%$ \\
\hline 6 & 20 & 800 & 0.1 & 1.6 & $63 \%$ \\
\hline 7 & 20 & 1100 & 1.5 & 0.5 & $87.60 \%$ \\
\hline 8 & 20 & 1500 & 1 & 0.8 & $83 \%$ \\
\hline 9 & 30 & 500 & 1 & 1.6 & $40 \%$ \\
\hline 10 & 30 & 800 & 1.5 & 1.3 & $85.90 \%$ \\
\hline 11 & 30 & 1100 & 0.1 & 0.8 & $67.30 \%$ \\
\hline 12 & 30 & 1500 & 0.5 & 0.5 & $54.50 \%$ \\
\hline 13 & 40 & 500 & 1.5 & 0.8 & $53.80 \%$ \\
\hline 14 & 40 & 800 & 1 & 0.5 & $58.30 \%$ \\
\hline 15 & 40 & 1100 & 0.5 & 1.6 & $88.30 \%$ \\
\hline 16 & 40 & 1500 & 0.1 & 1.3 & $81.70 \%$ \\
\hline $\mathrm{I}_{1}$ & 0.8150 & 0.5765 & 0.7345 & 0.7055 & \\
\hline $\mathrm{II}_{2}$ & 0.7215 & 0.6718 & 0.6483 & 0.6640 & \\
\hline $\mathrm{III}_{3}$ & 0.6193 & 0.8228 & 0.6680 & 0.7713 & \\
\hline $\mathrm{IV}_{4}$ & 0.7053 & 0.7900 & 0.8103 & 0.7203 & \\
\hline $\mathrm{R}$ & 0.1957 & 0.2463 & 0.1620 & 0.1073 & \\
\hline
\end{tabular}

\subsection{Relations between Frequency, Voltage and Dust Removal Efficiency}

According to the results of the above orthogonal table and anti-breakdown scope of electrodes, the electrodes of the 4th, 5th, 9th and 15th groups were selected in the experiment, and the electrode width and spacing of which are as follows: $1.5 \mathrm{~mm}$ and $1.6 \mathrm{~mm}, 0.5 \mathrm{~mm}$ and $1.3 \mathrm{~mm}, 1 \mathrm{~mm}$ and $1.6 \mathrm{~mm}$ and $0.5 \mathrm{~mm}$ and $1.6 \mathrm{~mm}$, respectively. The dust removal experiments were carried out under the different voltage and frequency, in order to find the optimal electrode width and spacing, frequency and voltage. The results were shown in Tables 2-5.

The experimental results show that low frequency is more advantageous to remove dust. The higher the voltage, the higher dust removal efficiency is. Considering the whole results, the 5th electrode is the best one. When electrode width is $0.5 \mathrm{~mm}$, spacing is $1.3 \mathrm{~mm}$, the voltage is $1500 \mathrm{~V}$, and the frequency is $15 \mathrm{~Hz}$, the largest dust removal efficiency can reach up to $99 \%$.

\subsection{Analysis between Waveform and Dust Removal Efficiency}

The impact of waveform on dust removal efficiency has been examined as well. Square wave, sine wave, triangular wave and sawtooth wave were applied respectively to the 5th electrode $(0.5 \mathrm{~mm}$ and $1.3 \mathrm{~mm})$, under 1500 $\mathrm{V}$ voltage and $15 \mathrm{~Hz}$ frequency. The dust removal effects were shown in Figure 2. From the results we know that the square wave has the best effect for dust removal, and the sine wave has the worst.

\subsection{Analysis between Duty Ratio and the Dust Removal Efficiency}

In view of the square wave, the influence of duty ratio on dust removal efficiency was also analyzed. The chosen duty ratio of the square wave is $10 \%, 20 \%, 30 \%, 20 \%$ and $50 \%$ respectively, under the optimal conditions in dust removal experiment, and the result was shown in Figure 3. It can be seen that the duty ratio have a significant impact on the dust removal efficiency, the higher the duty ratio, the smaller the dust removal efficiency. 


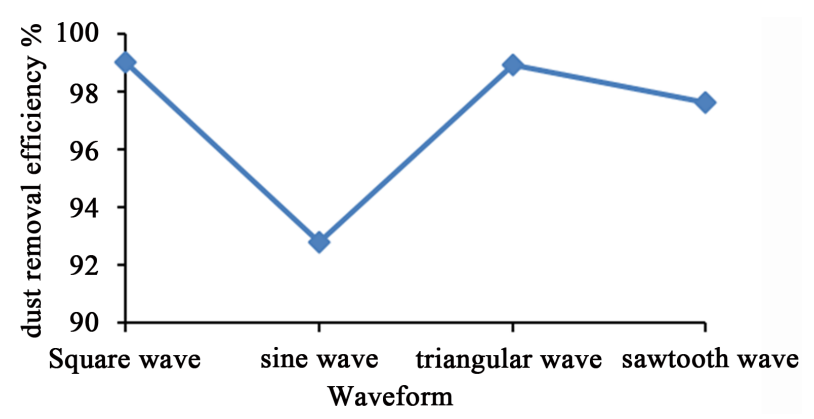

Figure 2. Impact of waveform on dust removal efficiency.

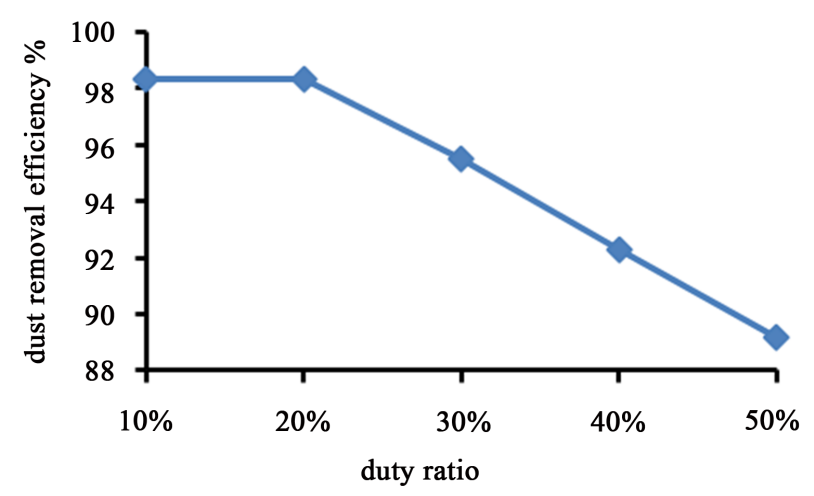

Figure 3. The influence of duty ratio on dust removal efficiency.

Table 2. The result of group 4 electrode $(1.5 \mathrm{~mm}, 1.6 \mathrm{~mm})$.

\begin{tabular}{|cccccccc}
\hline & Efficiency (\%) & Voltage (v) & & & & & \\
Frequency (Hz) & & & 1000 & 1200 & 1400 & 1500 \\
\hline & 5 & 22 & 43.9 & 75.6 & 76.8 & 81.7 \\
& 10 & 45.2 & 76.7 & 82.2 & 93.2 & 95.9 \\
& 15 & 15.5 & 22.3 & 44.7 & 89.3 & 93.2 \\
& 20 & 39.1 & 63.2 & 78.2 & 89.7 & 95.4 \\
& 30 & 32.5 & 67.5 & 77.5 & 91.3 & 92.5 \\
& 40 & 15.7 & 25.6 & 48.8 & 57 & 67.8 \\
\hline
\end{tabular}

Table 3. The result of group 5 electrode $(0.5 \mathrm{~mm}, 1.3 \mathrm{~mm})$.

\begin{tabular}{|c|c|c|c|c|c|}
\hline $\begin{array}{ll} & \text { Efficiency (\%) } \\
\text { Frequency }(\mathrm{Hz}) & \end{array}$ & 800 & 1000 & 1200 & 1400 & 1500 \\
\hline 5 & 49 & 72.1 & 91.3 & 94.2 & 95.2 \\
\hline 10 & 38.9 & 77.9 & 89.5 & 94.7 & 97.9 \\
\hline 15 & 30.5 & 59 & 87.6 & 97.1 & 99 \\
\hline 20 & 45.9 & 73.8 & 91 & 95.1 & 95.9 \\
\hline 30 & 43.8 & 75 & 88.5 & 93.8 & 97.9 \\
\hline 40 & 39.1 & 66.3 & 80.4 & 88 & 91.3 \\
\hline 50 & 33.3 & 54.1 & 55.9 & 57.7 & 59.5 \\
\hline
\end{tabular}


Table 4. The result of group 9 electrode $(1 \mathrm{~mm}, 1.6 \mathrm{~mm})$.

\begin{tabular}{|c|c|c|c|c|c|}
\hline $\begin{array}{ll} & \text { Efficiency (\%) } \\
\text { Frequency }(\mathrm{Hz}) & \end{array}$ & 800 & 1000 & 1200 & 1400 & 1500 \\
\hline 5 & 25.7 & 28.7 & 41.6 & 45.5 & 55.4 \\
\hline 10 & 65.2 & 69.7 & 78.7 & 86.5 & 95.5 \\
\hline 15 & 17 & 20.5 & 28.6 & 29.5 & 30.4 \\
\hline 20 & 55 & 59 & 60 & 61 & 65 \\
\hline 30 & 42.3 & 43.3 & 47.4 & 48.5 & 49.5 \\
\hline 40 & 32.6 & 60.5 & 61.6 & 62.8 & 64 \\
\hline 50 & 43.9 & 76.8 & 82.9 & 87.8 & 93.9 \\
\hline
\end{tabular}

Table 5. The result of group 15 electrode $(0.5 \mathrm{~mm}, 1.6 \mathrm{~mm})$.

\begin{tabular}{|c|c|c|c|c|c|}
\hline $\begin{array}{ll} & \text { Efficiency (\%) } \\
\text { Frequency }(\mathrm{Hz}) & \end{array}$ & 800 & 1000 & 1200 & 1400 & 1500 \\
\hline 5 & 27.5 & 56.9 & 74.5 & 86.3 & 90.2 \\
\hline 10 & 64.1 & 80.6 & 88.3 & 89.3 & 90.3 \\
\hline 15 & 27.2 & 44.6 & 66.3 & 83.7 & 87 \\
\hline 20 & 50.6 & 65.2 & 69.7 & 70.8 & 71.9 \\
\hline 30 & 56.6 & 68.4 & 69.7 & 75 & 92.1 \\
\hline 40 & 32.7 & 40.9 & 65.5 & 68.2 & 69.1 \\
\hline 50 & 30.6 & 34.7 & 64.3 & 83.7 & 84.7 \\
\hline
\end{tabular}

\section{Conclusion}

A series of ITO transparent fork electrodes with different width and spacing were designed, through the orthogonal experiment we know that the key factors influencing the efficiency of dust removal are the voltage and frequency. The 4th $(1.5 \mathrm{~mm}$ and $1.6 \mathrm{~mm})$, 5th $(0.5 \mathrm{~mm}$ and $1.3 \mathrm{~mm})$, 9th $(1 \mathrm{~mm}$ and $1.6 \mathrm{~mm})$ and 15 th $(0.5 \mathrm{~mm}$ and $1.6 \mathrm{~mm}$ ) electrodes were selected to carry on in-depth analysis of influence of the voltage and frequency on the dust removal efficiency. Furthermore, the influences of waveform and duty ratio on dust removal efficiency were analyzed as well, and the best conditions of dust removal are obtained, as follows: the voltage is $1500 \mathrm{~V}$, at a frequency of $15 \mathrm{~Hz}$, square wave, the duty ratio is $10 \%$, the electrode width is $0.5 \mathrm{~mm}$, and the electrode spacing is $1.3 \mathrm{~mm}$. Under the optimal conditions, dust removal efficiency can be as high as $99 \%$.

\section{References}

[1] Yuan, Y.F., Liu, M. and Bai, X.C. (2010) Research of Electrode Screen as Mitigation Technology. Spacecraft Engineering, 19, 89-94.

[2] Kawamoto, H. (2009) Electrostatic and Electromagnetic Cleaning of Lunar Dust Adhered to Spacesuits. Annual Meeting of LEAG, Lunar and Planetary Institute, Houston.

[3] Liu, G.Q., Li, S.Q., Liu, G.Q., et al. (2011) Characteristics of the Motion of Martian Dust Simulant on the TravellingWave Electric Curtain. Journal of Engineering Thermal Physics, 32, 2073-2075.

[4] Liu, G. and Marshall, J.S. (2010) Particle Transport by Standing Waves on an Electric Curtain. Journal of Electrostatics, 68, 289-298. http://dx.doi.org/10.1016/j.elstat.2010.02.004

[5] Qian, D., Marshall, J.S. and Frolik, J. (2012) Control Analysis for Solar Panel Dust Mitigation Using an Electric Curtain. Renewable Energy, 41, 134-144. http://dx.doi.org/10.1016/j.renene.2011.10.014

[6] Sun, Q.X., Yang, N.N., Xiao, Z.K., et al. (2012) Experimental Study on Efficiency of Dust Removal by Standing 
Wave Electric Curtain. Spacecraft Engineering, 21, 72-79.

[7] Liu, G.Q. and Marshall, J.S. (2010) Effect of Particle Adhesion and Interactions on Motion by Traveling Waves on an Electric Curtain. Journal of Electrostatics, 68, 179-189. http://dx.doi.org/10.1016/j.elstat.2009.12.007

[8] Zhou, C.D., He, G.F., Zhang, J., et al. (2013) Research on the Motion Pattern of Dust Particles and Self-Cleaning Mechanism of Solar Cells under Traveling-Wave Electric Curtain. Journal of Hebei University of Science and Technology, 34, 27-32.

[9] Wu, G.M., Yin, T.L., Tong, S., et al. (2013) Study of Dust Removal by Transparent Fork Electrodes. Integrated Ferroelectrics. 
Scientific Research Publishing (SCIRP) is one of the largest Open Access journal publishers. It is currently publishing more than 200 open access, online, peer-reviewed journals covering a wide range of academic disciplines. SCIRP serves the worldwide academic communities and contributes to the progress and application of science with its publication.

Other selected journals from SCIRP are listed as below. Submit your manuscript to us via either submit@scirp.org or Online Submission Portal.
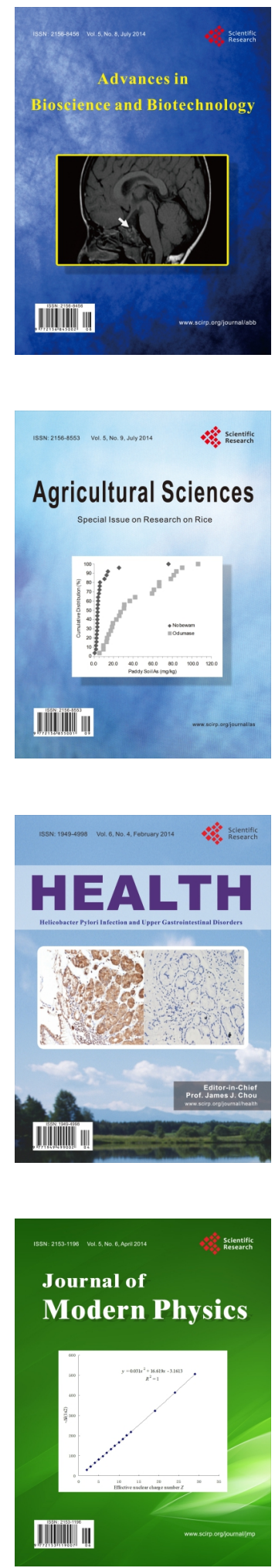
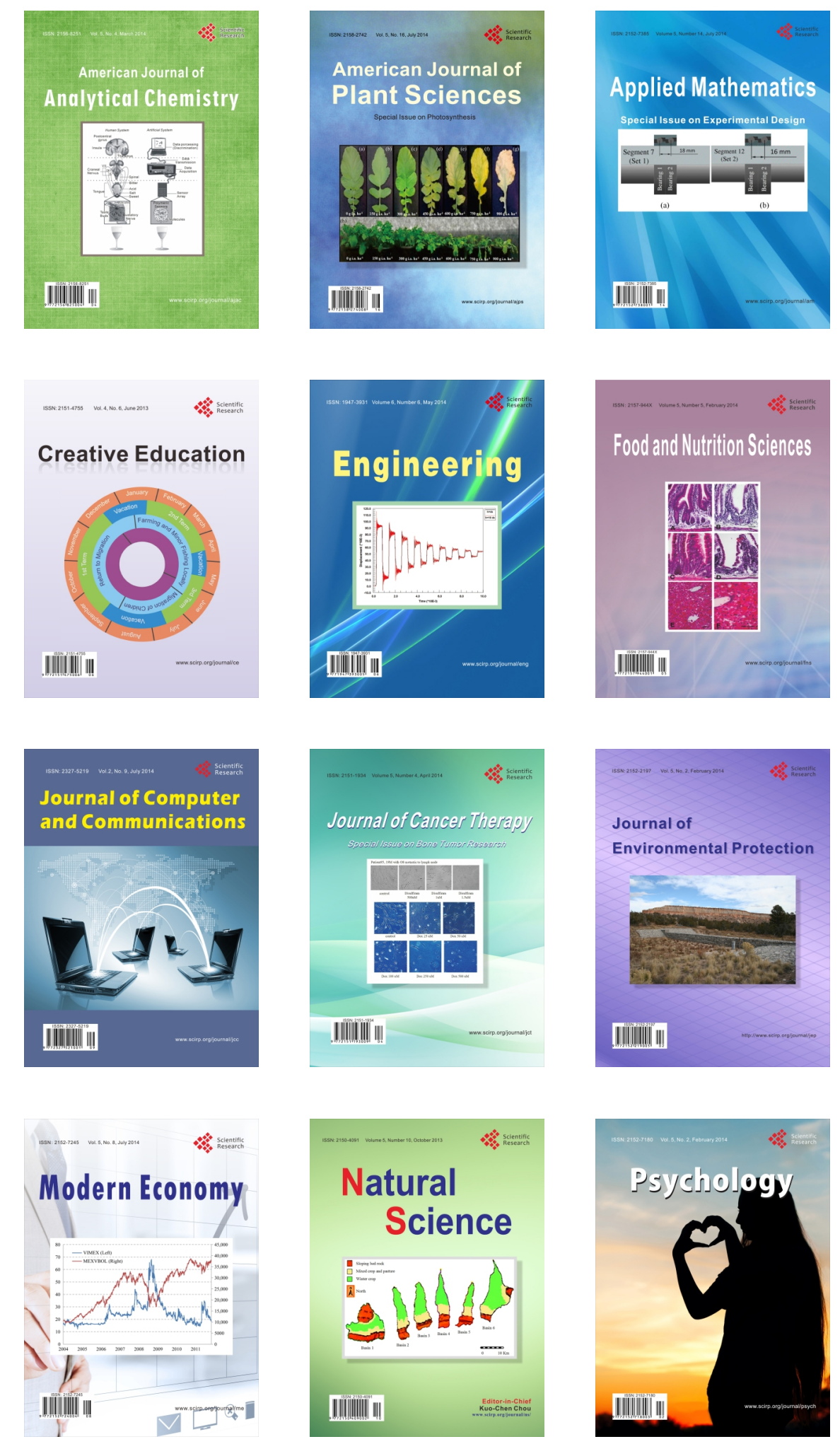